\title{
Editorial: A Need for a Universal Code of Ethics for Medical and Biological Engineers
}

\author{
Herbert F. Voigt \\ President, International Federation for Medical and Biological Engineering. Biomedical Engineer- \\ ing Department, Boston University, 44 Cummington Street, Boston MA 02215; Tel.: 617-353-2817; \\ Fax:617-353-6766; hfv@bu.edu.
}

\begin{abstract}
With each advance in biology, medicine and engineering, there are accompanying ethical issues that undoubtedly arise. Stem cells, synthetic biology, genetically-modified foods and organisms, cochlear implants and xenotransplantation are but a few areas that boast great potential, but can also stir great concern and generate fear. These advances and attending ethical dilemmas are emerging more rapidly than ever before. This new journal, Ethics in Biology, Engineering and Medicine (EBEM), will provide a forum for these important ethical issues and stands as an important repository for ethical discussions. The medical and biological engineering community welcomes this new journal and hopes that it will catalyze the discourse on creating a universal code of ethics for medical and biological engineers.
\end{abstract}

KEY WORDS: Medical Ethics; Engineering Ethics; Biomedical and Biological Engineering Ethics; Professional Ethics

The first step in the evolution of ethics is a sense of solidarity with other human beings.

\section{Albert Schweitzer}

With each advance in biology, medicine, and engineering, there are accompanying ethical issues that undoubtedly arise. Stem cells, synthetic biology, genetically modified foods and organisms, cochlear implants, and xenotransplantation are but a few areas that boast great potential, but can also stir great concern and generate fear. These advances and their attending ethical dilemmas are emerging more rapidly than ever before. While the former are often advanced subject areas in undergraduate and graduate biomedical engineering curricula, the latter are often relegated to a rather large set of elective courses - and ethics courses are usually not selected.

In the United States, the growth of biomedical engineering has been truly remarkable $^{1}$ and is entered nearly equally by the two genders. Growth in the job market is also expected to increase. According to the U.S. Bureau of Labor Statistics' Occupational Outlook Handbook, 2010-11 Edition", "Biomedical engineers are expected to have employment growth of 72 percent over the projections decade, much faster than the average for all occupations." In 2010, MSNBC announced that biomedical engineering is the fastest-growing profession in the United States ${ }^{3}$.

It appears that the fields of medical and biological engineering are also growing rapidly in Europe ${ }^{4}$ and Asia. ${ }^{5}$ The rise in the profession has been accompanied by an increase in the number of organizations serving these professionals. The International 
Federation for Medical and Biological Engineering (IFMBE), which celebrated its 50th anniversary in 2009, is made up of professional societies from 52 nations and five transnational societies. Not all of these societies have yet established a code of ethics, but this will clearly be needed for a profession that deals with health and well-being. Indeed, the code for medical and biological engineers should resemble the ethical code of the medical profession.

There have been a number of calls for the creation of a code of ethics for medical and biological engineering. ${ }^{1,6,7}$ The Biomedical Engineering Society introduced their code of ethics in 2004. The IFMBE has included creating such a code in their strategic plan. Moreover, the IFMBE's ethics committee has been charged recently to begin a review of its positions on a number of ethical issues. Very recently, the IFMBE's administrative committee voted to prohibit medical and biological engineers from participating in judicial executions. ${ }^{8}$

This new journal, Ethics in Biology, Engineering, and Medicine (EBEM), will provide a forum for these important ethical issues, and stands out as an important repository for ethical discussions. The medical and biological engineering community welcomes this new journal and hopes that it will catalyze the discourse on creating a universal code of ethics for medical and biological engineers.

Integrity without knowledge is weak and useless, and knowledge without integrity is dangerous and dreadful.

Samuel Johnson

\section{REFERENCES}

1. Enderle JD. Employment outlook and motivation for career preparation. In: Madhavan G, Oakley B, Kun L, Alberts B, Langer R, editors. Career development in bioengineering and biotechnology. New York: Springer Science+Business Media; 2008. p. 41-50.

2. Bureau of Labor Statistics, U.S. Department of Labor. Occupational outlook handbook, 2010-11 edition. Available from: http://www.bls.gov/OCO/.

3. MSNBC.com. 10 Fastest-growing professions: Opportunities abound for biomedical engineers, nurses, home health aides. Available from: www.msnbc.msn.com/id/34770373/ns/ business-careers/.

4. Nagel JH. Bioengineering and biotechnology: A European perspective. In: Madhavan G, Oakley B, Kun L, Alberts B, Langer R, editors. Career development in bioengineering and biotechnology. New York: Springer Science+Business Media; 2008. p. 21-32.

5. Kikuchi M, Goh JCH. Bioengineering and biotechnology: An Asia-Pacific perspective. In: Madhavan G, Oakley B, Kun L, Alberts B, Langer R, editors. Career development in bioengineering and biotechnology. New York: Springer Science+Business Media; 2008. p. 33-40.

6. Wood N, Barakat N. Inclusion of bio-engineering into existing codes of ethics. In: Proceedings of the 2009 American Society of Engineering Education (ASEE), North Central Section (NCS) Spring Conference, 2009 April 3-4, Grand Rapids, MI, USA. Washington, DC: ASEE; 2009.

7. Pienkowski D. The need for a professional code of ethics in biomedical engineering: A lesson from history. Crit Rev Biomed Eng. 2000;28(3-4):513-6. 
8. Voigt HF, Ehrmann DM. The ethical code for medical and biological engineers should preclude their role in judicial executions. Ethics in Biology, Engineering \& Medicine. 2010; 1: 43-52. 